\title{
Sagittal alignment of the cervical spine in the setting of adolescent idiopathic scoliosis
}

\author{
Michael Akbar, MD, ${ }^{1}$ Haidara Almansour, MD, MEng, ${ }^{1}$ Renaud Lafage, MSc, ${ }^{2}$ Bassel G. Diebo, MD, ${ }^{3}$ \\ Bernd Wiedenhöfer, MD, ${ }^{4}$ Frank Schwab, MD, ${ }^{2}$ Virginie Lafage, PhD, ${ }^{2}$ and Wojciech Pepke, MD ${ }^{1}$
}

\begin{abstract}
${ }^{1}$ Clinic for Orthopaedics and Trauma Surgery, Center for Orthopaedics, Trauma Surgery and Spinal Cord Injury, Heidelberg University Hospital, Heidelberg, Germany; ${ }^{2}$ Hospital for Special Surgery, New York, New York; ${ }^{3}$ Department of Orthopaedic Surgery, SUNY Downstate Medical Center, Brooklyn, New York; and ${ }^{4}$ ATOS Clinic Heidelberg, Germany
\end{abstract}

OBJECTIVE The goal of this study was to investigate the impact of thoracic and lumbar alignment on cervical alignment in patients with adolescent idiopathic scoliosis (AIS).

METHODS Eighty-one patients with AIS who had a Cobb angle $>40^{\circ}$ and full-length spine radiographs were included. Radiographs were analyzed using dedicated software to measure pelvic parameters (sacral slope [SS], pelvic incidence [PI], pelvic tilt [PT]); regional parameters (C1 slope, $\mathrm{C} 0-\mathrm{C} 2$ angle, chin-brow vertical angle [CBVA], slope of line of sight [SLS], McRae slope, McGregor slope [MGS], C2-7 [cervical lordosis; CL], C2-7 sagittal vertical axis [SVA], C2-T3, C2-T3 SVA, C2-T1 Harrison measurement [C2-T1 Ha], T1 slope, thoracic kyphosis [TK], lumbar lordosis [LL], and PILL mismatch); and global parameters (SVA). Patients were stratified by their lumbar alignment into hyperlordotic (LL > $59.7^{\circ}$ ) and normolordotic ( $\mathrm{LL} 39.3^{\circ}$ to $59.7^{\circ}$ ) groups and also, based on their thoracic alignment, into hypokyphotic (TK < $-33.1^{\circ}$ ) and normokyphotic (TK $-33.1^{\circ}$ to $-54.9^{\circ}$ ) groups. Finally, they were grouped based on their global alignment into either an anterior-aligned group or a posterior-aligned group.

RESULTS The lumbar hyperlordotic group, in comparison to the normolordotic group, had a significantly larger LL, SS, $\mathrm{PI}$ (all $p<0.001)$, and TK ( $p=0.014)$ and a significantly smaller PI-LL mismatch $(p=0.001)$. Lumbar lordosis had no influence on local cervical parameters.

The thoracic hypokyphotic group had a significantly larger PI-LL mismatch $(p<0.002)$ and smaller T1 slope $(p<0.001)$, and was significantly more posteriorly aligned than the normokyphotic group (-15.02 \pm 8.04 vs $13.54 \pm 6.17$ [mean \pm SEM], $p=0.006)$. The patients with hypokyphotic AIS had a kyphotic cervical spine (cervical kyphosis [CK]) $(p<0.001)$. Furthermore, a posterior-aligned cervical spine in terms of C2-7 SVA $(p<0.006)$ and C2-T3 SVA $(p<0.001)$ was observed in the thoracic hypokyphotic group.

Comparing patients in terms of global alignment, the posterior-aligned group had a significantly smaller T1 slope $(p<$ 0.001 ), without any difference in terms of pelvic, lumbar, and thoracic parameters when compared to the anterior-aligned group. The posterior-aligned group also had a CK (-9.20 \pm 1.91 vs $5.21 \pm 2.95$ [mean $\pm S E M], p<0.001)$ and a more posterior-aligned cervical spine, as measured by C2-7 SVA ( $p=0.003)$ and C2-T3 SVA $(p<0.001)$.

CONCLUSIONS Alignment of the cervical spine is closely related to thoracic curvature and global alignment. In patients with AIS, a hypokyphotic thoracic alignment or posterior global alignment was associated with a global cervical kyphosis. Interestingly, upper cervical and cranial parameters were not statistically different in all investigated groups, meaning that the upper cervical spine was not recruited for compensation in order to maintain a horizontal gaze.

https://thejns.org/doi/abs/10.3171/2018.3.SPINE171263

KEYWORDS sagittal alignment; cervical spine; AIS; adolescent idiopathic scoliosis; cervical alignment; cervical lordosis; cervical kyphosis; deformity

\footnotetext{
ABBREVIATIONS AIS = adolescent idiopathic scoliosis; CBVA = chin-brow vertical angle; $\mathrm{CK}=$ cervical kyphosis; $\mathrm{CL}=$ cervical lordosis; $\mathrm{C} 2-\mathrm{T} 1 \mathrm{Ha}=\mathrm{C} 2-\mathrm{T} 1 \mathrm{Harrison}$ measurement; LL = lumbar lordosis; MGS = McGregor slope; PI = pelvic incidence; PT = pelvic tilt; SLS = slope of line of sight; SS = sacral slope; SVA = sagittal vertical axis; TK = thoracic kyphosis.
}

SUBMITTED December 4, 2017. ACCEPTED March 14, 2018.

INCLUDE WHEN CITING Published online August 24, 2018; DOI: 10.3171/2018.3.SPINE171263. 
$\mathrm{S}$ coliosis is a three-dimensional deformity of the spine that includes a coronal curve, vertebral rotation, and flattening of the sagittal profile. ${ }^{16,28}$ Adolescent idiopathic scoliosis (AIS) occurs in approximately 2\%-3\% of the general population. ${ }^{24}$ Recently, the main focus of investigation has been on spinopelvic parameters and the sagittal profile measured by established parameters such as pelvic incidence (PI), pelvic tilt (PT), sacral slope (SS), lumbar lordosis (LL), thoracic kyphosis (TK), and sagittal vertical axis (SVA), ${ }^{2,8,22,23}$ However, little effort has been put forth to describe the relationship between cervical alignment and global posture. ${ }^{5}$ A deeper understanding of sagittal cervical alignment in AIS and its correlation with regional and global spinopelvic parameters is still needed.

Hilibrand et al. in 1995 reported a relationship between thoracic hypokyphosis and cervical kyphosis $(\mathrm{CK})$ in preoperative patients. ${ }^{11}$ Furthermore, the relationship between cervical spine alignment and global spine curvature in the coronal and sagittal planes was recognized by MacThiong et al. in $2003 .{ }^{23}$ In addition, a correlation between cervical lordosis (CL) and TK was identified in a study by Scheer et al. ${ }^{26}$ However, these studies did not include detailed parameters to allow elucidation of the intricate relationships between cervical alignment and sagittal profile. Due to the clinical relevance of the deviations of cervical alignment in AIS on surgical decision-making, a more detailed investigation to untangle the complex influences of the sagittal profile on cervical alignment is warranted.

One of the fundamental goals in the surgical treatment of AIS is the maintenance or restoration of normal sagittal alignment by using the Cotrel-Dubousset technique.? With this surgical method combined with Ponte osteotomy, ${ }^{27}$ it is possible to correct hypokyphosis of the thoracic spine while preserving a normal LL in a notable percentage of patients with AIS. ${ }^{2,8,17}$ Recent clinical and radiological investigations of surgically treated patients showed a correlation between the loss of normal TK and the development of $\mathrm{CK}$, which was associated with frequent axial neck pain..$^{15,30}$ It has already been shown that sagittal plane correction of the thoracic spine can influence cervical alignment., 3 We hypothesized that cervical alignment in nonsurgically treated patients with AIS is affected by regional and global alignment of the spine. The purpose of this study was to test this hypothesis by evaluating the impact of thoracic, lumbar, and global alignment on cervical alignment.

\section{Methods \\ Patient Population}

Eighty-one consecutive patients with AIS who had a Cobb angle $>40^{\circ}$ and in whom anterior-posterior and lateral full-length radiographs of the spine were obtained between 2008 and 2014 were included in this retrospective single-center study. Patients who fulfilled the aforementioned criteria were included regardless of their sagittal balance. Clinical and demographic characteristics were obtained from medical records. The institutional review board of our institution approved this study.

\section{Radiographic Acquisition}

All radiographs were obtained with the patient in a standing position. Patients were barefoot, had both upper extremities crossed over the chest, and were instructed to look straight ahead in a relaxed position. Radiographs that failed to fulfill these requirements were excluded. Additional exclusion criteria were cases of neuromuscular and congenital scoliosis. All radiographic data were saved as DICOM (Digital Imaging and Communications in Medicine) files and exported from PACS (Picture Archiving and Communication System) to dedicated software to be analyzed. The SpineView software was used to assess the different parameters included in this study. All measurements were performed by the senior spine surgeon and first author (M.A.).

\section{Data Collection and Radiographic Analysis}

Radiographic parameters included the following: 1) pelvic parameters: PI, PT, SS; 2) regional alignment: LL, TK; 3) lower cervical: CL C2-7 (negative value denotes CK), cervical SVA C2-7 (C2-7 SVA), C2-T3 cervicothoracic SVA (C2-T3 SVA), C2-T1 Harrison measurement (C2-T1 Ha); 4) upper cervical: $\mathrm{C} 1$ slope, $\mathrm{C} 2$ slope, $\mathrm{C} 0-\mathrm{C} 2$ angle; 5) cranial: chin-brow vertical angle (CBVA), slope of line of sight (SLS), McRae slope (C0 slope), McGregor slope (MGS); and 6) global alignment: SVA (Fig. 1).

The $\mathrm{C} 2-\mathrm{T} 1 \mathrm{Ha}$; the sum of cervical segmental angles between posterior tangents of C2-3, C3-4, C4-5, C5-6, C6-7, and C7-T1; and the segmental slip were quantified (Fig. 1).

\section{Patient Stratification}

Sagittal alignment was evaluated and compared with normative values in children and in the adolescent population as published by Mac-Thiong et al. ${ }^{22}$ According to these normative data, patients were stratified by their lumbar alignment into hyperlordotic $\left(>59.7^{\circ}\right)$ or lordotic $\left(36.3^{\circ}\right.$ to $\left.59.7^{\circ}\right)$ and by their thoracic alignment into hypokyphotic $\left(>-33 \cdot 1^{\circ}\right)$ or kyphotic $\left(-33 \cdot 1^{\circ}\right.$ to $\left.-54.9^{\circ}\right)$. Patients were considered to have an anterior alignment if the SVA was $>0 \mathrm{~mm}$ and a posterior alignment if the SVA was $\leq 0 \mathrm{~mm}$.

\section{Statistical Analysis}

Descriptive statistics were reported as either the mean \pm SD or the mean \pm SEM, as indicated. Independent t-tests were used for intergroup comparisons. The threshold of statistical significance was set at $\mathrm{p}<0.05$. Statistical software package IBM SPSS 20.00 (IBM Corp.) was used for statistical analysis.

\section{Results}

Eighty-one patients with AIS (26\% male vs $74 \%$ female) with a mean age $( \pm \mathrm{SD})$ of $15.5( \pm 3.5)$ years (range 10-19 years) were included.

\section{Stratification by LL}

The lumbar hyperlordotic group, when compared to the normolordotic group, had a significantly greater LL $\left(68^{\circ}\right.$ vs $\left.48^{\circ}\right)$, greater SS $\left(46^{\circ}\right.$ vs $\left.35^{\circ}\right)$, higher PI $\left(59^{\circ}\right.$ vs $\left.47^{\circ}\right)($ all $\mathrm{p}<0.001)$, greater TK $\left(-42^{\circ}\right.$ vs $\left.-32^{\circ}\right)(\mathrm{p}=0.014)$, 

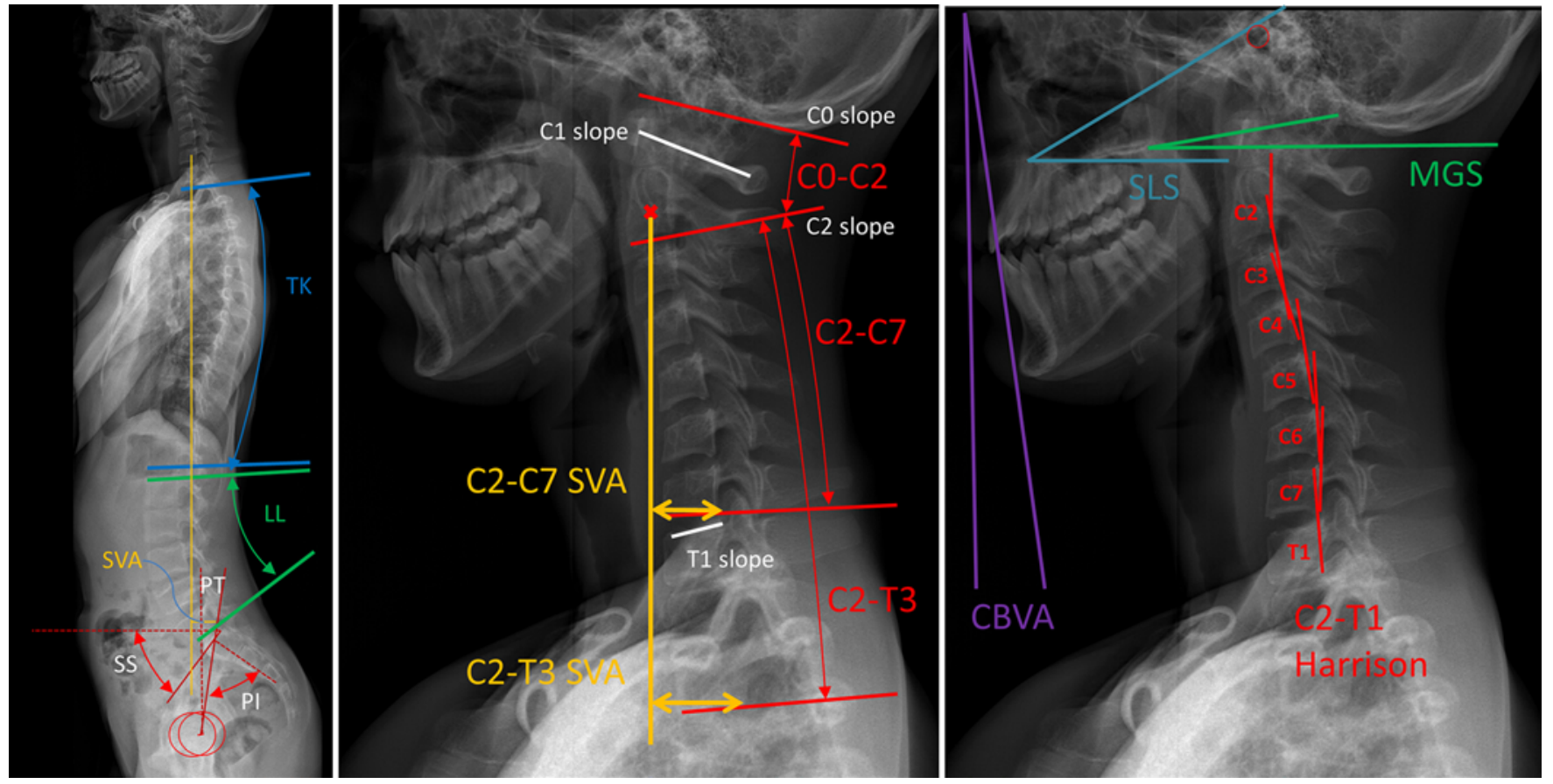

FIG. 1. Radiographs of the spine overlaid with schematic presentation of horizontal gaze, upper cervical, lower cervical, thoracic, lumbar, and spinopelvic parameters. Horizontal gaze: CBVA, SLS, McRae slope, and MGS. Upper cervical: C0 slope, C1 slope, C2 slope, and C0-C2 angle. Lower cervical: C2-7, C2-7 SVA, C2-T3, C2-T3 SVA, and C2-T1 Ha. Thoracic: T1 slope and TK. Lumbar: LL. Global alignment: SVA. Figure is available in color online only.

and significantly smaller PI-LL mismatch $\left(-10^{\circ}\right.$ vs $\left.-1^{\circ}\right)(\mathrm{p}$ $=0.001$ ) (Table 1). In terms of global alignment, the hyperlordotic group was more posteriorly aligned (SVA -10 $\mathrm{mm}$ vs $11.1 \mathrm{~mm}, \mathrm{p}<0.05)$. In addition, lower cervical, upper cervical, and horizontal gaze parameters did not reach statistical significance between these two groups (Table 1). No significant difference in terms of cervical curvature (C2-T1 Ha) was noted. Notably, when cervical segmental slip was analyzed, only the C4-5 segment revealed a significant slip (Fig. 2).

\section{Stratification by TK}

The thoracic hypokyphotic group, when compared to the normokyphotic group, had a significantly larger PI-LL mismatch $\left(0.2^{\circ}\right.$ vs $\left.-8.7^{\circ}, \mathrm{p}<0.002\right)$, smaller $\mathrm{T} 1$ slope $\left(11^{\circ}\right.$ vs $28^{\circ}, \mathrm{p}<0.001$ ), and more posterior global alignment (SVA $-15 \mathrm{~mm}$ vs $13.5 \mathrm{~mm}, \mathrm{p}<0.006$ ). Interestingly, all measured parameters of the lower cervical spine, with the exception of the $\mathrm{C} 2$ slope, revealed a strong statistical difference between the two groups $(\mathrm{p}<0.001)$ (Table 1). The patients with hypokyphotic AIS had a larger CK (C2-7: $-11.9^{\circ}$ vs $5.5^{\circ}$; $\mathrm{C} 2-\mathrm{T} 3:-16.5^{\circ}$ vs $2.7^{\circ}$; $\mathrm{C} 2-\mathrm{T} 1 \mathrm{Ha}:-5.8^{\circ}$ vs $16.1^{\circ}$; all $\left.\mathrm{p}<0.001\right)$ and a smaller T1 slope $\left(11.1^{\circ}\right.$ vs $27.7^{\circ}$, $\mathrm{p}<0.001$ ) when compared to the normokyphotic group (Fig. 3). Furthermore, patients with hypokyphotic AIS had a more posteriorly aligned cervical spine in terms of C2-7 SVA ( $26 \mathrm{~mm}$ vs $36.2 \mathrm{~mm}, \mathrm{p}=0.006)$ and C2-T3 SVA ( 38.2 $\mathrm{mm}$ vs $62.9 \mathrm{~mm}, \mathrm{p}<0.001$ ) (Table 1, Fig. 4). The C2-T1 Ha showed a significant segmental kyphotic alignment across the four lower cervical segments (C4-5, C5-6, C6-7, C7$\mathrm{T} 1 ; \mathrm{p}<0.01)$. Finally, a cervical segmental slip of the lower cervical spine was noted (C3-4, C4-5, C5-6, C6-7; p < 0.01) (Fig. 5). Upper cervical spine and horizontal gaze parameters were not statistically different (Table 1).

\section{Stratification by Global Alignment (SVA)}

The posterior-aligned group had a significantly smaller $\mathrm{T} 1$ slope $\left(15^{\circ}\right.$ vs $\left.26^{\circ}, \mathrm{p}<0.001\right)$ compared to the anterioraligned group, without any difference identified in pelvic, lumbar, or thoracic parameters. The posterior-aligned group had a larger cervical kyphosis $\left(\mathrm{C} 2-7\right.$ : $-9.2^{\circ}$ vs $5.2^{\circ}$; C2-T3: $-12.8^{\circ}$ vs $1.7^{\circ}$; C2-T1 Ha: $-0.7^{\circ}$ vs $15.3^{\circ}$; all $\mathrm{p}<$ 0.001 ) and a more posterior-aligned cervical spine $\mathrm{C} 2-7$ SVA (26.1 $\mathrm{mm}$ vs $37.4 \mathrm{~mm}, \mathrm{p}=0.003)$ and $\mathrm{C} 2-\mathrm{T} 3 \mathrm{SVA}$ (42.8 $\mathrm{mm}$ vs $61.9 \mathrm{~mm}, \mathrm{p}<0.001)$ (Fig. 6). There was no important difference between these groups in terms of upper cervical parameters or horizontal gaze parameters, with the exception of SLS $\left(10.4^{\circ}\right.$ vs $\left.-1.6^{\circ}, \mathrm{p}=0.027\right)$ (Table 1). This stratification also revealed a difference regarding cervical curvature as a segmental kyphotic alignment was observed (C3-4, C4-5, C5-6; p < 0.005). Finally, a cervical sagittal slip in two segments (C3-4, C5-6) was observed (Fig. 7). The majority of patients in this study were globally aligned, with a mean SVA of $1.19 \pm 46.37$ $\mathrm{mm}($ mean $\pm \mathrm{SD})$.

\section{Discussion}

Cervical kyphosis seems to be prevalent both in patients with AIS and in normal adolescents..$^{1418}$ Scoliosis affects the sagittal profile and could concomitantly influence cervical sagittal alignment. The effects of AIS on the 
TABLE 1. Stratification by LL, TK, and SVA: intergroup comparison of spinopelvic parameters

\begin{tabular}{|c|c|c|c|c|c|c|c|c|c|c|c|c|c|c|c|}
\hline Parameter* & $\begin{array}{l}\text { Group } \\
\text { Lordosis }\end{array}$ & Mean & SD & SEM & $p$ Value & $\begin{array}{l}\text { Group } \\
\text { Kyphosis }\end{array}$ & Mean & SD & SEM & $p$ Value & $\begin{array}{c}\text { Global } \\
\text { Alignment }\end{array}$ & Mean & SD & SEM & $\begin{array}{c}p \\
\text { Value }\end{array}$ \\
\hline \multirow[t]{2}{*}{$\operatorname{SS}\left({ }^{\circ}\right)$} & $\mathrm{NL}$ & 35.11 & 9.90 & 1.51 & \multirow[t]{2}{*}{$<0.001$} & NK & 39.11 & 11.16 & 1.65 & \multirow[t]{2}{*}{0.179} & Pst & 38.30 & 11.10 & 1.76 & \multirow[t]{2}{*}{0.069} \\
\hline & $\mathrm{HL}$ & 46.51 & 7.57 & 1.23 & & HK & 42.22 & 9.50 & 1.61 & & Ant & 42.56 & 9.60 & 1.50 & \\
\hline \multirow[t]{2}{*}{$\mathrm{PT}\left({ }^{\circ}\right)$} & $\mathrm{NL}$ & 12.15 & 7.36 & 1.12 & \multirow[t]{2}{*}{0.982} & NK & 11.36 & 8.51 & 1.25 & \multirow[t]{2}{*}{0.302} & Pst & 12.62 & 7.74 & 1.22 & \multirow[t]{2}{*}{0.629} \\
\hline & $\mathrm{HL}$ & 12.19 & 9.06 & 1.47 & & $\mathrm{HK}$ & 13.23 & 7.64 & 1.29 & & Ant & 11.73 & 8.60 & 1.34 & \\
\hline \multirow[t]{2}{*}{$\mathrm{PI}\left({ }^{\circ}\right)$} & $\mathrm{NL}$ & 47.26 & 12.93 & 1.97 & \multirow[t]{2}{*}{$<0.001$} & NK & 50.47 & 14.76 & 2.18 & \multirow[t]{2}{*}{0.095} & Pst & 50.92 & 13.05 & 2.06 & \multirow[t]{2}{*}{0.270} \\
\hline & $\mathrm{HL}$ & 58.70 & 12.03 & 1.95 & & HK & 55.46 & 11.78 & 1.99 & & Ant & 54.29 & 14.27 & 2.23 & \\
\hline \multirow[t]{2}{*}{ PI-LL $\left({ }^{\circ}\right)$} & $\mathrm{NL}$ & -0.61 & 11.95 & 1.82 & \multirow[t]{2}{*}{0.001} & NK & -8.72 & 11.47 & 1.69 & \multirow[t]{2}{*}{$<0.002$} & Pst & -7.02 & 9.67 & 1.53 & \multirow[t]{2}{*}{0.135} \\
\hline & $\mathrm{HL}$ & -9.66 & 12.23 & 1.98 & & HK & 0.22 & 12.91 & 2.18 & & Ant & -2.75 & 15.14 & 2.36 & \\
\hline \multirow{2}{*}{$\begin{array}{l}\mathrm{LL}(\mathrm{L} 1-\mathrm{S} 1) \\
\quad\left({ }^{\circ}\right)\end{array}$} & $\mathrm{NL}$ & 47.87 & 9.21 & 1.41 & \multirow[t]{2}{*}{$<0.001$} & NK & 59.20 & 13.43 & 1.98 & \multirow[t]{2}{*}{0.165} & Pst & 57.94 & 13.59 & 2.15 & \multirow[t]{2}{*}{0.757} \\
\hline & $\mathrm{HL}$ & 68.37 & 5.90 & 0.96 & & $\mathrm{HK}$ & 55.23 & 12.01 & 2.03 & & Ant & 57.04 & 12.37 & 1.93 & \\
\hline \multirow{2}{*}{$\begin{array}{c}\text { TK (T2-12) } \\
\left({ }^{\circ}\right)\end{array}$} & $\mathrm{NL}$ & -32.41 & 16.52 & 2.52 & 0.014 & NK & -47.77 & 12.30 & 1.81 & $<0.001$ & Pst & -33.13 & 12.56 & 1.99 & 0.059 \\
\hline & $\mathrm{HL}$ & -41.63 & 16.46 & 2.67 & & HK & -22.23 & 10.04 & 1.70 & & Ant & -40.26 & 20.01 & 3.12 & \\
\hline SVA $(\mathrm{mm})$ & $\mathrm{NL}$ & 11.10 & 48.00 & 7.32 & 0.039 & NK & 13.54 & 41.88 & 6.17 & $<0.006$ & Pst & -35.27 & 26.45 & 4.18 & $<0.001$ \\
\hline & $\mathrm{HL}$ & -10.01 & 42.32 & 6.87 & & HK & -15.02 & 47.56 & 8.04 & & Ant & 36.78 & 31.48 & 4.92 & \\
\hline $\operatorname{T1S}\left({ }^{\circ}\right)$ & $\mathrm{NL}$ & 20.56 & 13.20 & 2.01 & 0.996 & NK & 27.74 & 9.73 & 1.43 & $<0.001$ & Pst & 15.04 & 9.28 & 1.47 & $<0.001$ \\
\hline & $\mathrm{HL}$ & 20.57 & 10.68 & 1.73 & & $\mathrm{HK}$ & 11.14 & 7.28 & 1.23 & & Ant & 25.95 & 12.02 & 1.88 & \\
\hline $\mathrm{C} 2-7\left(^{\circ}\right)$ & $\mathrm{NL}$ & -1.82 & 17.07 & 2.70 & 0.950 & NK & 5.52 & 16.77 & 2.53 & $<0.001$ & Pst & -9.20 & 11.44 & 1.91 & $<0.001$ \\
\hline & $\mathrm{HL}$ & -1.57 & 17.13 & 2.90 & & HK & -11.96 & 11.09 & 1.99 & & Ant & 5.21 & 18.41 & 2.95 & \\
\hline C2-7 SVA & $\mathrm{NL}$ & 32.53 & 16.18 & 2.56 & 0.775 & NK & 36.23 & 17.41 & 2.62 & $<0.006$ & Pst & 26.11 & 14.49 & 2.41 & 0.003 \\
\hline$(\mathrm{mm})$ & $\mathrm{HL}$ & 31.41 & 17.43 & 2.95 & & $\mathrm{HK}$ & 26.01 & 13.70 & 2.46 & & Ant & 37.45 & 16.87 & 2.70 & \\
\hline $\mathrm{C} 2-\mathrm{T} 3\left(^{\circ}\right)$ & $\mathrm{NL}$ & -5.11 & 17.71 & 2.80 & 0.944 & NK & 2.68 & 21.03 & 3.17 & $<0.001$ & Pst & -12.80 & 13.67 & 2.28 & $<0.001$ \\
\hline & $\mathrm{HL}$ & -5.44 & 22.71 & 3.84 & & HK & -16.55 & 11.57 & 2.08 & & Ant & 1.69 & 22.53 & 3.61 & \\
\hline C2-T3 SVA & $\mathrm{NL}$ & 52.08 & 25.63 & 4.05 & 0.801 & NK & 62.96 & 23.76 & 3.58 & $<0.001$ & Pst & 42.83 & 17.42 & 2.90 & $<0.001$ \\
\hline$(\mathrm{mm})$ & $\mathrm{HL}$ & 53.47 & 22.02 & 3.72 & & HK & 38.21 & 14.95 & 2.69 & & Ant & 61.87 & 25.51 & 4.08 & \\
\hline $\mathrm{C} 2-\mathrm{T} 1 \mathrm{Ha}$ & $\mathrm{NL}$ & 6.87 & 20.00 & 3.24 & 0.851 & NK & 16.10 & 18.52 & 2.82 & $<0.001$ & Pst & -0.75 & 12.89 & 2.15 & $<0.001$ \\
\hline$\left({ }^{\circ}\right)$ & $\mathrm{HL}$ & 7.74 & 19.20 & 3.29 & & HK & -5.80 & 12.37 & 2.30 & & Ant & 15.31 & 21.73 & 3.62 & \\
\hline $\mathrm{C} 2 \mathrm{~S}\left({ }^{\circ}\right)$ & $\mathrm{NL}$ & 21.53 & 11.45 & 1.81 & 0.767 & NK & 21.37 & 13.62 & 2.05 & 0.638 & Pst & 23.70 & 8.44 & 1.41 & 0.210 \\
\hline & $\mathrm{HL}$ & 22.35 & 12.30 & 2.08 & & $\mathrm{HK}$ & 22.68 & 8.67 & 1.56 & & Ant & 20.27 & 14.09 & 2.26 & \\
\hline $\operatorname{C1S}\left({ }^{\circ}\right)$ & $\mathrm{NL}$ & -8.42 & 8.68 & 1.74 & 0.357 & NK & -7.06 & 11.73 & 2.22 & 0.994 & Pst & -7.95 & 8.67 & 1.61 & 0.500 \\
\hline & $\mathrm{HL}$ & -5.78 & 11.34 & 2.22 & & HK & -7.08 & 7.97 & 1.66 & & Ant & -5.91 & 11.87 & 2.53 & \\
\hline $\cos \left({ }^{\circ}\right)$ & $\mathrm{NL}$ & -1.49 & 6.24 & 1.33 & 0.407 & NK & 0.30 & 7.44 & 1.49 & 0.277 & Pst & -0.99 & 5.91 & 1.29 & 0.743 \\
\hline & $\mathrm{HL}$ & 0.32 & 7.61 & 1.70 & & $\mathrm{HK}$ & -1.99 & 5.97 & 1.45 & & Ant & -0.27 & 7.90 & 1.72 & \\
\hline $\mathrm{CO}-\mathrm{C} 2$ & NL & 23.07 & 8.69 & 1.90 & 0.631 & NK & 20.44 & 10.61 & 2.17 & 0.093 & Pst & 23.67 & 6.28 & 1.44 & 0.397 \\
\hline angle ( & $\mathrm{HL}$ & 21.66 & 9.60 & 2.20 & & $\mathrm{HK}$ & 25.34 & 4.96 & 1.24 & & Ant & 21.26 & 11.00 & 2.40 & \\
\hline $\operatorname{MGS}\left({ }^{\circ}\right)$ & $\mathrm{NL}$ & 3.27 & 6.14 & 1.41 & 0.330 & NK & 5.80 & 7.50 & 1.68 & 0.112 & Pst & 4.46 & 5.14 & 1.15 & 0.862 \\
\hline & $\mathrm{HL}$ & 5.40 & 6.73 & 1.63 & & $\mathrm{HK}$ & 2.37 & 4.24 & 1.06 & & Ant & 4.05 & 7.92 & 1.98 & \\
\hline $\operatorname{SLS}\left({ }^{\circ}\right)$ & $\mathrm{NL}$ & 5.99 & 8.95 & 3.16 & 0.567 & NK & 7.66 & 9.39 & 2.97 & 0.767 & Pst & 10.41 & 6.71 & 2.02 & 0.027 \\
\hline & $\mathrm{HL}$ & 8.62 & 8.39 & 3.17 & & HK & 6.33 & 7.23 & 3.23 & & Ant & -1.57 & 6.77 & 3.38 & \\
\hline $\operatorname{CBVA}\left({ }^{\circ}\right)$ & $\mathrm{NL}$ & 9.81 & 11.10 & 4.20 & 0.318 & NK & 8.98 & 10.62 & 4.34 & 0.795 & Pst & 9.09 & 8.62 & 3.52 & 0.791 \\
\hline & $\mathrm{HL}$ & 4.78 & 3.74 & 2.16 & & HK & 7.28 & 9.13 & 4.56 & & Ant & 7.12 & 12.11 & 6.06 & \\
\hline
\end{tabular}

Ant = anterior; $\mathrm{COS}=\mathrm{C} 0$ slope; $\mathrm{C} 1 \mathrm{~S}=\mathrm{C} 1$ slope; $\mathrm{C} 2 \mathrm{~S}=\mathrm{C} 2$ slope; $\mathrm{HK}=$ hypokyphotic; $\mathrm{HL}=$ hyperlordotic; $\mathrm{NK}=$ normokyphotic; $\mathrm{NL}=$ normolordotic; pst = posterior; $\mathrm{T} 1 \mathrm{~S}$ $=\mathrm{T} 1$ slope.

Boldface type indicates statistical significance at $p<0.05$.

* Upper cervical: C1S, C2S, and C0-C2 angle; lower cervical: C2-7, C2-7 SVA, C2-T3, C2-T3 SVA, and C2-T1 Ha; thoracic and lumbar: SS, PT, PI, LL, PI-LL, TK, and SVA; cranial: COS (McRae slope), MGS, SLS, and CBVA.

cervical spine are particularly relevant at present, given that recent research has focused on whether cervical kyphosis represents a physiological state of alignment or is a predictor for a later pathology. ${ }^{1,69,21,25}$ Despite recent attempts to highlight cervical alignment and its interaction with the global and regional sagittal profiles, ${ }^{1,25,31}$ the findings of these investigations did not include detailed parameters to identify this potentially underlying rela- 


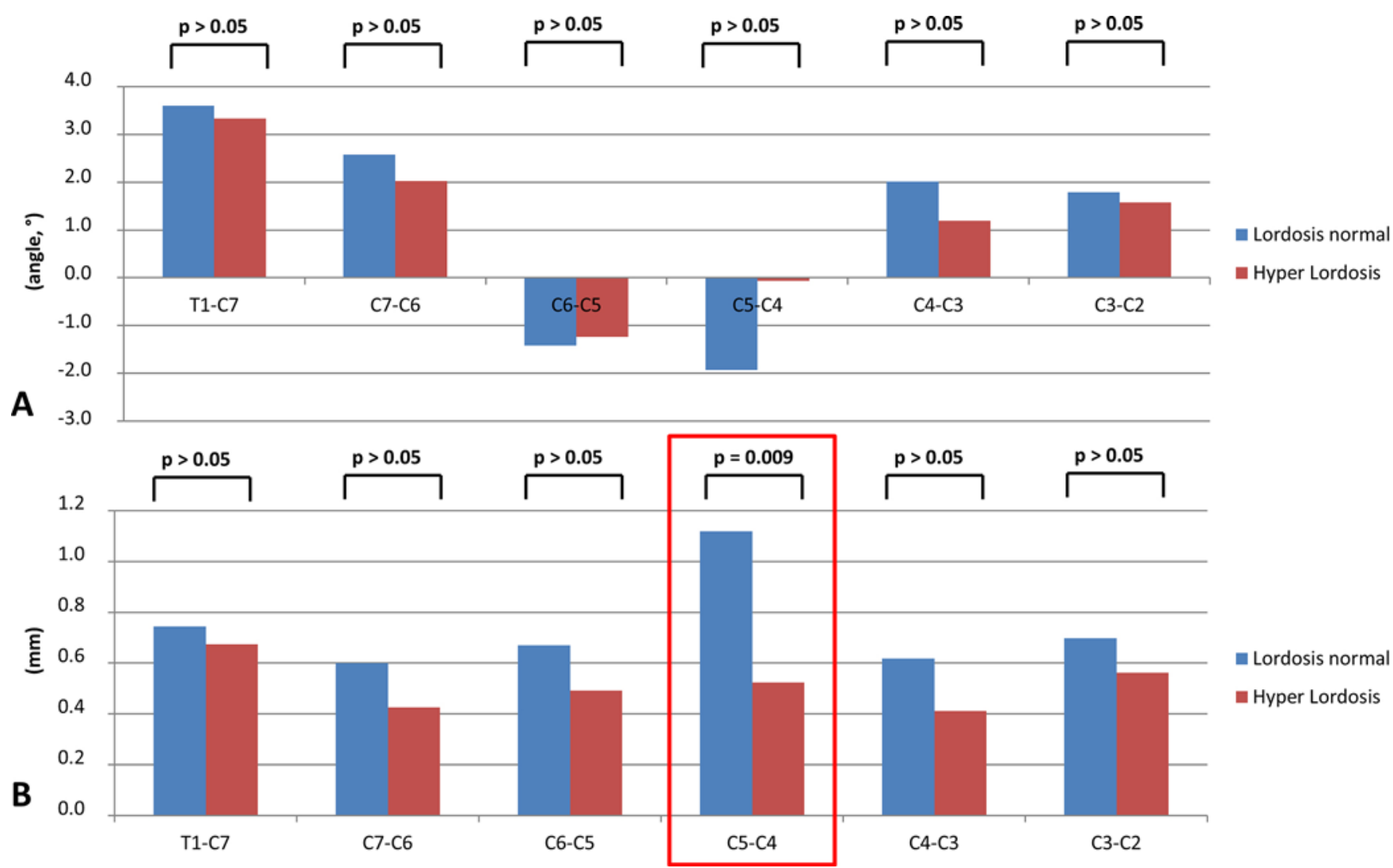

FIG. 2. Bar graphs with the sum of posterior tangents for cervical segments (A, expressed as angle $\left.\left[^{\circ}\right]\right)$ and segmental cervical slip (B, expressed in millimeters [mm]) measured according to LL; only the C4-5 segment revealed a significant slip (red box). Negative value denotes cervical kyphosis. Figure is available in color online only.

tionship. In our opinion, the collective understanding of the interdependence between sagittal profile and cervical alignment in patients with AIS is incomplete. Thus, this study addresses this gap to gain a deeper understanding of the impact of sagittal alignment on the cervical spine.

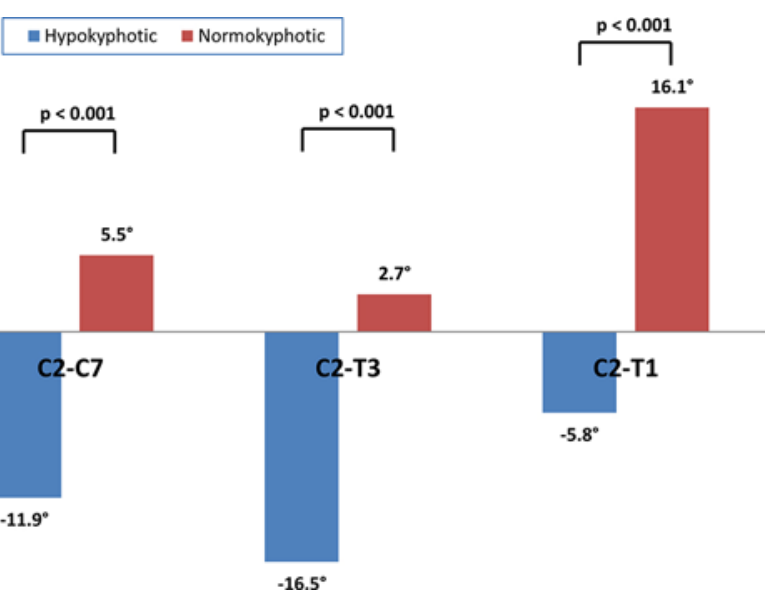

FIG. 3. Bar graph with comparison of cervical parameters C2-7, C2-T3, and $\mathrm{C} 2-\mathrm{T} 1$ between subgroups: thoracic hypokyphosis versus normokyphosis (negative value denotes $\mathrm{CK}$ ). Data expressed as angle $\left(^{\circ}\right)$. Figure is available in color online only.
Our findings reveal that in patients with AIS, thoracic hypokyphosis is associated with a decrease in cervical lordosis in the lowest segments and an increase in cervical kyphosis in the middle segments. This could be ex-

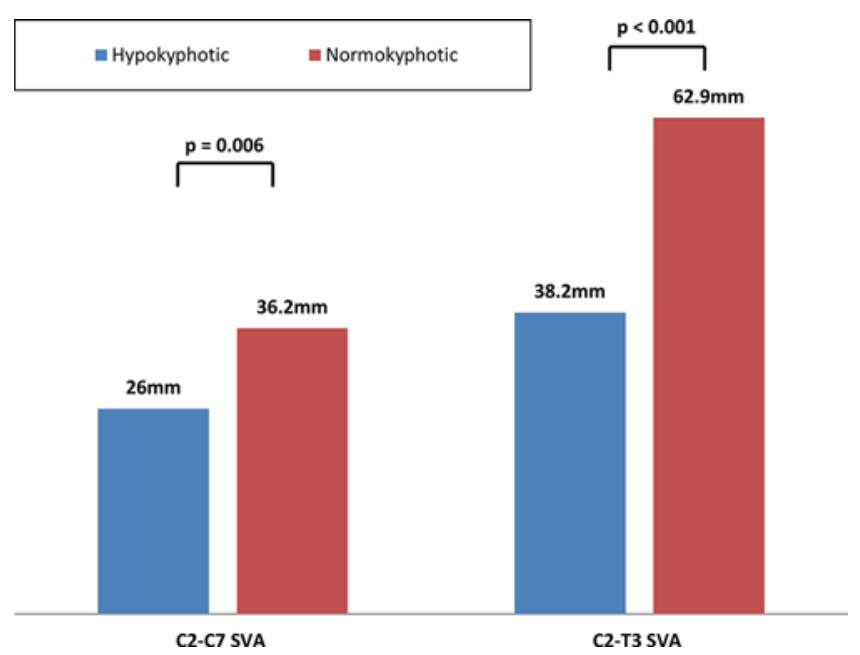

FIG. 4. Bar graph with comparison of cervical C2-7 SVA and C2-T3 SVA between subgroups: thoracic hypokyphosis versus normokyphosis. Data expressed in millimeters $(\mathrm{mm})$. Figure is available in color online only. 


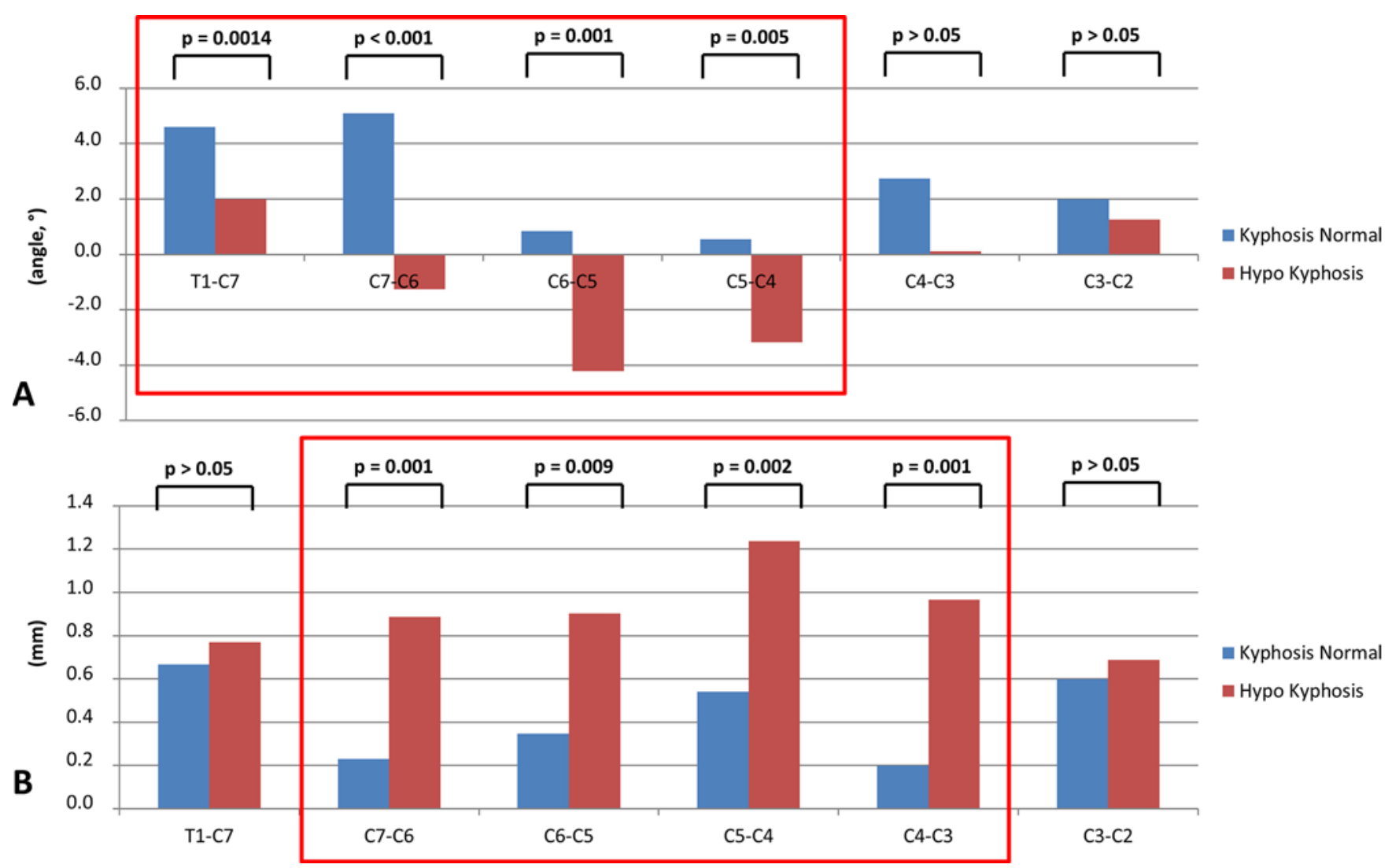

FIG. 5. Bar graphs with sum of posterior tangents for cervical segments (A, expressed as angle $\left.\left[^{\circ}\right]\right)$ and segmental cervical slip (B, expressed in millimeters [mm]) measured according to TK. A cervical segmental slip of the lower cervical spine was noted (red boxes). Negative value denotes CK. Figure is available in color online only.

plained by the relationship between thoracic kyphosis and T1 slope. Our results show that patients with hypokyphosis have a decreased $\mathrm{T} 1$ slope; these results are corroborated by Lee et al. (2015). ${ }^{20}$ Furthermore, Lee et al. (2012) have already shown that the T1 slope is a key player in predicting lower cervical alignment. ${ }^{19}$ In the context of these previous findings, our results underscore the necessity for further research into whether thoracic hypokyphosis is the cause of the observed cervical kyphosis. In addition, this study showed that patients with hypokyphotic AIS were more posteriorly aligned (SVA $<-15 \mathrm{~mm}$ ) and had greater cervical kyphosis. One explanation can be that patients with a hypokyphotic spine that is posteriorly aligned recruit cervical kyphosis as a compensatory mechanism to position the cranium over the pelvis. This is in line with findings from Diebo et al., who suggested that in patients with normal horizontal gaze, thoracolumbar alignment and TK affect cervical alignment. They recognized that posterior global alignment and flattening of the thoracic spine lead to progressive cervical kyphosis. ${ }^{6}$ Our patients also had a posterior-aligned cervical spine (C2-7 SVA and C2-T3 SVA). This could be explained by their smaller T1 slope. Tang et al. described a significant correlation between T1 slope and C2-7 SVA. ${ }^{29}$

Interestingly, when patients were stratified by their global alignment (SVA) with no differences in their TK or LL, a significant decrease in T1 slope was observed in the posterior-aligned group. Furthermore, in this group it was observed that the lower cervical spine was recruited for compensation by increasing cervical kyphosis. Although the patients with posterior alignment were not malaligned, their posterior alignment may have influenced their cervical spine conformation. By influencing T1 slope, posterior alignment led to more kyphosis of the lower cervical spine..$^{20}$ This could be a compensatory mechanism that was recruited to keep the cranium near the center of gravity.

On the other hand, when our patients were grouped according to their LL, we noted that an increased LL was associated with an increased TK and a posterior alignment (SVA). In contrast, there was no significant difference in T1 slope or in all measured cervical and horizontal gaze parameters. Thus, LL has no notable influence on CL. Our data confirm results of Hiyama et al., who also noted no correlation between CL and LL in patients with AIS. ${ }^{12}$ This is probably explained by sufficient thoracic compensation mechanisms due to hyperlordosis, making it unnecessary for further compensation from the cervical spine.

Up to this point, only the lower cervical spine has been discussed, because statistical significance was limited to the lower segments. This raises another question: was the upper cervical spine consistent across all patient subgroups? Our findings show that upper cervical parameters and horizontal gaze parameters did not exhibit any change, regardless of how patients were stratified. However, our description of 


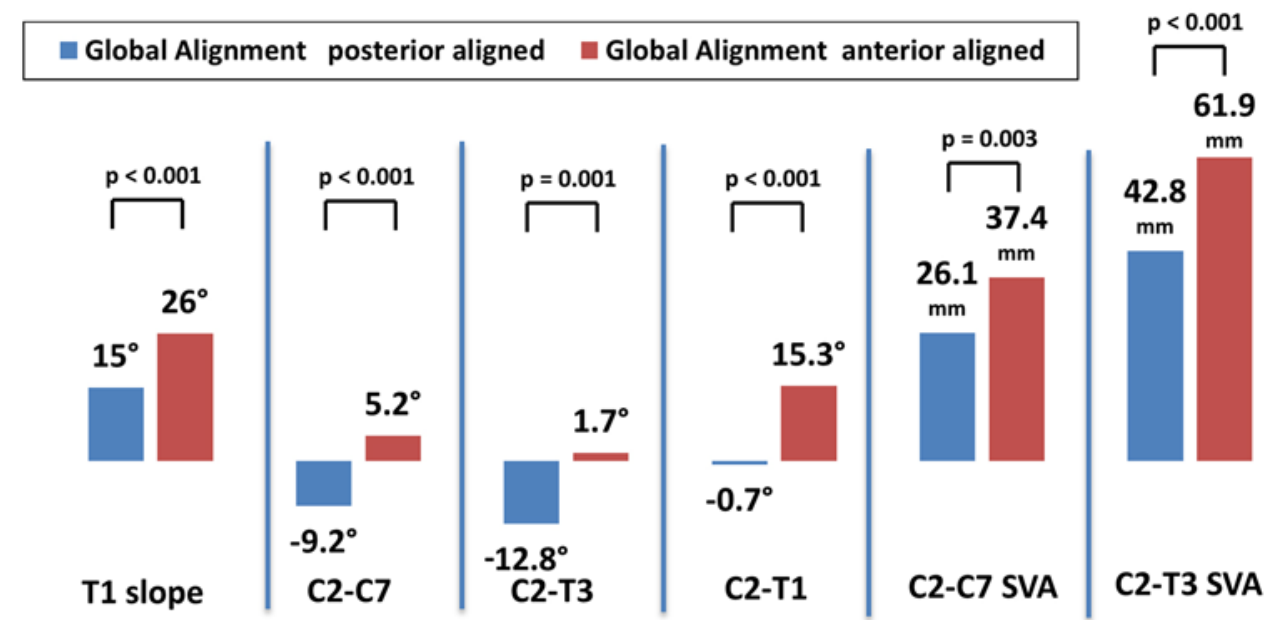

FIG. 6. Bar graph with comparison of cervical parameters C2-7, C2-T3, C2-T1, C2-7 SVA, and C2-T3 SVA between subgroups: anteriorly aligned versus posteriorly aligned (negative value denotes CK). Data for cervical parameters expressed as angle $\left({ }^{\circ}\right)$ and SVA expressed in millimeters $(\mathrm{mm})$. Figure is available in color online only.

the posture of the patients with thoracic hypokyphosis who had a posterior alignment, a smaller T1 slope, and a larger cervical kyphosis still lacks a substantial element: the reaction of the upper spine. We interpreted the consistency of the upper cervical parameters as a mechanism to maintain horizontal gaze, resulting in a cervical spine with kyphosis of its lower segments and lordosis of its upper segments. This is consistent with the findings of Charles et al., who noted that correction of the sagittal posture in patients with AIS has no influence on CBVA or CO-C2 angle. ${ }^{4}$

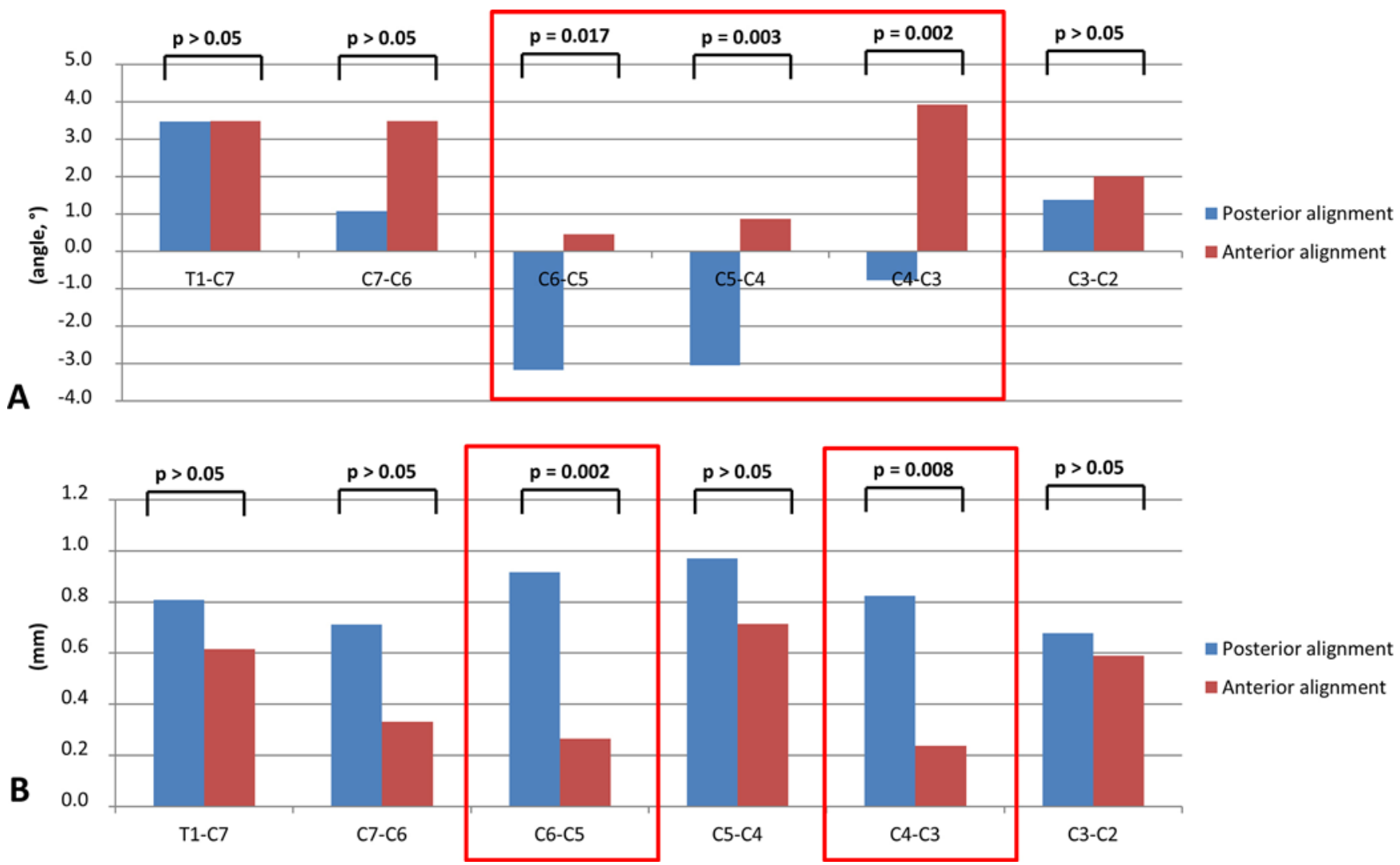

FIG. 7. Bar graphs with sum of posterior tangents for cervical segments (A, expressed as angle $\left.\left[^{\circ}\right]\right)$ and segmental cervical slip (B, expressed in millimeters [mm]) measured according to global alignment. A cervical sagittal slip in two segments $(C 3-4, C 5-6)$ was observed (red boxes). Negative value denotes CK. Figure is available in color online only. 
What also differentiates this study from previous investigations into cervical sagittal alignment is the study of segmental cervical kyphosis and a possible accompanying sagittal anterolisthesis. Segmental kyphosis was quantified by $\mathrm{C} 2-\mathrm{T} 1 \mathrm{Ha}$, which is considered to be the best measure of cervical curvature..$^{10,26}$ As Fig. 4 illustrates, between the thoracic hypo- and normokyphotic groups there is moderate overlap between the severity of segmental kyphosis and the amount of sagittal anterolisthesis (segments C4-5, C5-6, C6-7). Notably, this caused no clinical symptoms in our patients with AIS.

Finally, the clinical relevance of these findings permeates many aspects of healthcare for both adolescents and the elderly. Le Huec et al. have shown that more than one-third of their asymptomatic volunteers had a cervical kyphosis..$^{18}$ Our patients with AIS who had a thoracic hypokyphosis associated with a cervical kyphosis were also asymptomatic. Nevertheless, we must ask the question: will these patients remain asymptomatic, or does their cervical kyphosis represent the beginning of a pathological process?

Progressive cervical kyphosis is reported to be associated with myelopathy. ${ }^{26}$ This poses a challenge in surgical planning for the correction of AIS because health-related quality of life parameters correlate with C2-7 SVA, showing more pain and disability with postoperative malalignment of cervical sagittal parameters. ${ }^{29}$ Further studies should be performed to investigate whether cervical spine kyphosis in adolescents is a predictor for future disability.

One of the limitations of this study is that due to its retrospective design, we could not correlate cervical parameters with health-related quality of life data. Hence, the link between our radiographic findings and clinical symptoms could not be established. We acknowledge another limitation with regard to the characteristics of our study cohort that limits the elucidation of gender-associated changes related to cervical sagittal alignment: the unequal distribution of gender $(26 \%[n=21]$ males, $74 \%[n=60]$ females) would bias the results of an intergender subanalysis required to reveal those differences. These limitations notwithstanding, our retrospective analysis revealed important associations and enabled us to disentangle complex relationships between the cervical and thoracic spine and its interplay with global alignment in patients with AIS.

\section{Conclusions}

Cervical alignment in patients with AIS is influenced by TK and global alignment (SVA). Patients with thoracic hypokyphosis and posterior alignment had a cervical kyphosis. We recommend that cervical alignment should be considered when planning to correct the sagittal profile in patients with AIS due to the potential debilitating impact of cervical kyphosis in adulthood.

\section{References}

1. Aykac B, Ayhan S, Yuksel S, Guler UO, Pellise F, Alanay A, et al: Sagittal alignment of cervical spine in adult idiopathic scoliosis. Eur Spine J 24:1175-1182, 2015

2. Bridwell KH, Betz R, Capelli AM, Huss G, Harvey C: Sagittal plane analysis in idiopathic scoliosis patients treated with Cotrel-Dubousset instrumentation. Spine (Phila Pa 1976) 15:921-926, 1990
3. Canavese F, Turcot K, De Rosa V, de Coulon G, Kaelin A: Cervical spine sagittal alignment variations following posterior spinal fusion and instrumentation for adolescent idiopathic scoliosis. Eur Spine J 20:1141-1148, 2011

4. Charles YP, Sfeir G, Matter-Parrat V, Sauleau EA, Steib JP: Cervical sagittal alignment in idiopathic scoliosis treated by posterior instrumentation and in situ bending. Spine (Phila Pa 1976) 40:E419-E427, 2015

5. Cochran T, Irstam L, Nachemson A: Long-term anatomic and functional changes in patients with adolescent idiopathic scoliosis treated by Harrington rod fusion. Spine (Phila Pa 1976) 8:576-584, 1983

6. Diebo BG, Challier V, Henry JK, Oren JH, Spiegel MA, Vira $S$, et al: Predicting cervical alignment required to maintain horizontal gaze based on global spinal alignment. Spine (Phila Pa 1976) 41:1795-1800, 2016

7. Dubousset J, Cotrel Y: Application technique of CotrelDubousset instrumentation for scoliosis deformities. Clin Orthop Relat Res (264):103-110, 1991

8. Halm H, Castro WH, Jerosch J, Winkelmann W: Sagittal plane correction in "King-classified" idiopathic scoliosis patients treated with Cotrel-Dubousset instrumentation. Acta Orthop Belg 61:294-301, 1995

9. Harrison DD, Troyanovich SJ, Harrison DE, Janik TJ, Murphy DJ: A normal sagittal spinal configuration: a desirable clinical outcome. J Manipulative Physiol Ther 19:398-405, 1996

10. Harrison DE, Harrison DD, Cailliet R, Troyanovich SJ, Janik TJ, Holland B: Cobb method or Harrison posterior tangent method: which to choose for lateral cervical radiographic analysis. Spine (Phila Pa 1976) 25:2072-2078, 2000

11. Hilibrand AS, Tannenbaum DA, Graziano GP, Loder RT, Hensinger RN: The sagittal alignment of the cervical spine in adolescent idiopathic scoliosis. J Pediatr Orthop 15:627632,1995

12. Hiyama A, Sakai D, Watanabe M, Katoh H, Sato M, Mochida $\mathrm{J}$ : Sagittal alignment of the cervical spine in adolescent idiopathic scoliosis: a comparative study of 42 adolescents with idiopathic scoliosis and 24 normal adolescents. Eur Spine J 25:3226-3233, 2016

13. Ilharreborde B, Vidal C, Skalli W, Mazda K: Sagittal alignment of the cervical spine in adolescent idiopathic scoliosis treated by posteromedial translation. Eur Spine J 22:330337,2013

14. Ito K, Imagama S, Ito Z, Ando K, Kobayashi K, Hida T, et al: Analysis of cervical kyphosis and spinal balance in young idiopathic scoliosis patients classified by the apex of thoracic kyphosis. Eur Spine J 25:3220-3225, 2016

15. Katsuura A, Hukuda S, Saruhashi Y, Mori K: Kyphotic malalignment after anterior cervical fusion is one of the factors promoting the degenerative process in adjacent intervertebral levels. Eur Spine J 10:320-324, 2001

16. Kojima T, Kurokawa T: Quantitation of three-dimensional deformity of idiopathic scoliosis. Spine (Phila Pa 1976) 17 (3 Suppl):S22-S29, 1992

17. Labelle H, Dansereau J, Bellefleur C, de Guise J, Rivard CH, Poitras B: Peroperative three-dimensional correction of idiopathic scoliosis with the Cotrel-Dubousset procedure. Spine (Phila Pa 1976) 20:1406-1409, 1995

18. Le Huec JC, Demezon H, Aunoble S: Sagittal parameters of global cervical balance using EOS imaging: normative values from a prospective cohort of asymptomatic volunteers. Eur Spine J 24:63-71, 2015

19. Lee SH, Kim KT, Seo EM, Suk KS, Kwack YH, Son ES: The influence of thoracic inlet alignment on the craniocervical sagittal balance in asymptomatic adults. J Spinal Disord Tech 25:E41-E47, 2012

20. Lee SH, Son ES, Seo EM, Suk KS, Kim KT: Factors determining cervical spine sagittal balance in asymptomatic adults: correlation with spinopelvic balance and thoracic inlet alignment. Spine J 15:705-712, 2015 
21. Lippa L, Lippa L, Cacciola F: Loss of cervical lordosis: What is the prognosis? J Craniovertebr Junction Spine 8:9-14, 2017

22. Mac-Thiong JM, Labelle H, Berthonnaud E, Betz RR, Roussouly P: Sagittal spinopelvic balance in normal children and adolescents. Eur Spine J 16:227-234, 2007

23. Mac-Thiong JM, Labelle H, Charlebois M, Huot MP, de Guise JA: Sagittal plane analysis of the spine and pelvis in adolescent idiopathic scoliosis according to the coronal curve type. Spine (Phila Pa 1976) 28:1404-1409, 2003

24. Negrini S, Aulisa AG, Aulisa L, Circo AB, de Mauroy JC, Durmala J, et al: 2011 SOSORT guidelines: orthopaedic and rehabilitation treatment of idiopathic scoliosis during growth. Scoliosis 7:3, 2012

25. Norheim EP, Carreon LY, Sucato DJ, Lenke LG, Glassman SD: Cervical spine compensation in adolescent idiopathic scoliosis. Spine Deform 3:327-331, 2015

26. Scheer JK, Tang JA, Smith JS, Acosta FL Jr, Protopsaltis TS, Blondel B, et al: Cervical spine alignment, sagittal deformity, and clinical implications: a review. J Neurosurg Spine 19:141-159, 2013

27. Shah SA, Dhawale AA, Oda JE, Yorgova P, Neiss GI, Holmes $\mathrm{L} \mathrm{Jr}$, et al: Ponte osteotomies with pedicle screw instrumentation in the treatment of adolescent idiopathic scoliosis. Spine Deform 1:196-204, 2013

28. Stokes IA, Bigalow LC, Moreland MS: Three-dimensional spinal curvature in idiopathic scoliosis. J Orthop Res 5:102113,1987

29. Tang JA, Scheer JK, Smith JS, Deviren V, Bess S, Hart RA, et al: The impact of standing regional cervical sagittal alignment on outcomes in posterior cervical fusion surgery. Neurosurgery 76 (Suppl 1):S14-S21, 2015

30. Wang L, Liu X: Cervical sagittal alignment in adolescent idiopathic scoliosis patients (Lenke type 1-6). J Orthop Sci 22:254-259, 2017

31. Yukawa Y, Kato F, Suda K, Yamagata M, Ueta T, Yoshida
M: Normative data for parameters of sagittal spinal alignment in healthy subjects: an analysis of gender specific differences and changes with aging in 626 asymptomatic individuals. Eur Spine J 27:426-432, 2018

\section{Disclosures}

Dr. V. Lafage owns stock in Nemaris, Inc. She receives support for non-study-related clinical or research effort that she oversees from SRS, NASS (grants), DePuy Spine, K2M, Stryker, and NuVasive (NuVasive funds paid through ISSGF). She is a consultant for NuVasive and has speaking and/or teaching arrangements with AOSpine and DePuy Spine. Dr. Schwab owns stock in Nemaris, Inc. He receives support for non-study-related clinical or research effort that he oversees from DePuy Spine, NuVasive, Stryker, and K2M. He is a consultant for MSD, Zimmer-Biomet, Medicrea, NuVasive, and K2M. He has speaking and/or teaching arrangements with MSD, Zimmer-Biomet, Medicrea, NuVasive, and $\mathrm{K} 2 \mathrm{M}$.

\section{Author Contributions}

Conception and design: Pepke, Akbar. Acquisition of data: Pepke, Akbar. Analysis and interpretation of data: Pepke, Akbar, Almansour. Drafting the article: Pepke, Akbar, Almansour. Critically revising the article: Pepke, Akbar, Almansour, Diebo, Wiedenhöfer, Schwab, V Lafage. Reviewed submitted version of manuscript: all authors. Statistical analysis: R Lafage. Study supervision: Akbar.

\section{Correspondence}

Wojciech Pepke: Heidelberg University Hospital, Heidelberg, Germany.wojciech.pepke@med.uni-heidelberg.de. 